\title{
Adhesive zinc tape treatment of uncomplicated ulcers amongst leprosy outpatients
}

\author{
A KUMAR \& M LAKSHMANAN \\ Division of Epidemiology and Statistics, Central Leprosy Teaching \\ and Research Institute, Chingleput (TN), India
}

Accepted for publication 5 June 1985

\begin{abstract}
Summary The operational feasibility of ordinary adhesive zinc tape treatment of ulcers under field conditions, was studied on 89 uncomplicated superficial ulcers amongst 50 leprosy outpatients. Deep ulcers with or without sinus and purulent discharge were not considered fit for tape treatment. All the 13 hand ulcers and 62 $(82 \%)$ of the 76 plantar ulcers healed in $3 \cdot 8 \pm 2 \cdot 1$ and $9 \cdot 5 \pm 7 \cdot 6$ weeks of tape treatment, while patients were ambulatory. The tape treatment was found to be effective, economical, acceptable and convenient to patients, and operationally feasible. The available adhesive leucoblast may be used for ulcer treatment in field and hospital situations.
\end{abstract}

\section{Introduction}

The timely and regular management of ulcers on anaesthetic hands and feet of leprosy patients is necessary to prevent the deformities of limbs. Since our mobile leprosy clinics function only once a month, ulcer patients find it very difficult to get their ulcers dressed regularly. It is not feasible either to provide gauze and bandage to patients or hospitalize them for treating their simple plantar ulcers. This makes it necessary to find some simple, effective, economical, and operationally feasible method(s) of ulcer treatment, by patients themselves with little training and supervision.

The role of zinc in wound healing, especially amongst zinc deficient persons like those suffering with burns and leprosy, is now well established. The ordinary adhesive zinc tape has been used for healing local wounds, over many years. ${ }^{1,7,9}$ The zinc tape treated wounds have been demonstrated to heal in shorter periods than gauze and bandage/sponge treated ones. ${ }^{2,}{ }^{4}$ One study ${ }^{8}$ has reported the ordinary adhesive zinc tape treatment of ulcers amongst leprosy patients to be very successful. Later another study ${ }^{6}$ compared the adhesive zinc tape treatment, with gauze and bandage treatment, of simple plantar ulcers amongst their hospitalized leprosy patients, and found the tape treatment healed ulcers in a shorter period. 
Since it is not feasible to admit patients to treat their simple plantar ulcers, the present project was specifically undertaken to study the operational feasibility of adhesive zinc tape treatment of uncomplicated ulcers under our field conditions. The comparison of tape treatment with other methods of ulcer treatment as well as the pathogenesis of ulceration and its recurrence, were not envisaged in this operational study.

\section{Materials and methods}

The study was carried out amongst outpatients attending a mobile treatment unit, operating in Rural Field Operation Area (Sriperumbudur Taluk of Chingleput District) of Central Leprosy Teaching and Research Institute, Chingleput, Tamil Nadu. Fifty adult leprosy patients (32 males and 18 females) with 93 uncomplicated superficial ulcers with or without serous discharge were included in the trial. Complicated ulcers (deep ulcers with or without sinus and purulent discharge) were not considered fit for adhesive zinc tape treatment. More than $91 \%$ of the selected patients were agricultural labourers, belonging to the low income group. All patients had grade 1 or 2 (WHO classification) disabilities.

Of the 44 patients with 76 plantar ulcers, only 27 patients with 45 plantar ulcers wore locally available plastic chappals/shoes for an average period of $2 \cdot 34 \pm 2 \cdot 99$ (SD) years before getting ulcer(s), and most of them continued to do so during the tape treatment. In order to study the effect of tape treatment under ordinary circumstances of non-availability of proper footwear to large numbers of patients, the efforts were not made to equip the trial patients with microcellular rubber footwear; on average each patient walked for $4 \cdot 5 \pm 2 \cdot 2$ (SD) $\mathrm{km} / \mathrm{day}$.

Of the 93 ulcers, 4 plantar ulcers amongst 2 male patients were not dressed regularly by them, hence these were excluded from the trial. The distribution of the remaining 89 ulcers ( 76 plantar and 13 hand) treated with adhesive tape is shown in Figure 1. All the 89 ulcers were classified into 3 groups according to their area, namely: (1) Small with $\leqslant 2 \mathrm{sq} \mathrm{cm}$ area $(73 \%)$, (2) Medium with $2 \cdot 1-4 \mathrm{sq} \mathrm{cm}$ area $(10 \cdot 1 \%)$, and (3) Big with $>4 \mathrm{sq} \mathrm{cm}$ area $(16 \cdot 9 \%)$. All the ulcers on hands were small in size. About $64 \%$ of ulcers were of recent duration up to 3 months, while about $15 \%$ were more than one year old. The mean duration of each hand and plantar ulcer was $0 \cdot 10 \pm 0 \cdot 16$ and $0 \cdot 84 \pm 2 \cdot 0$ years, respectively. Most of these ulcers followed a blister $(70 \%)$ or injury $(16 \%)$ at the site, whereas in $14 \%$ of ulcers the reason was not specified. Only 69 ulcers (65 plantar and 4 hand) showed minimal-moderate serous discharge.

The adhesive zinc tape used in this trial was made of a plastic web coated with an adhesive substance composed of gum, resin and approximately $30 \%$ zinc oxide. The tape was fixed on a readily removable siliconized kraft paper, thereby making it easy for distribution and application on ulcers, even by patients with anaesthetic finger stumps. Each roll of tape measured $2.5 \mathrm{~cm} \times 5 \mathrm{~m}$. 


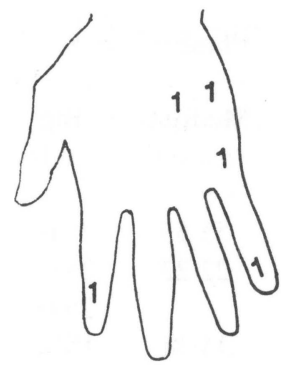

RIGHT 5

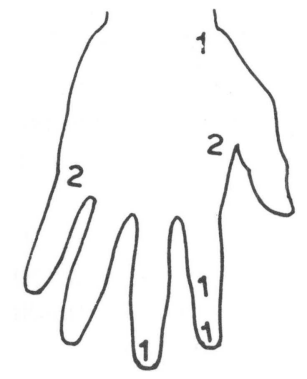

LEFT 8

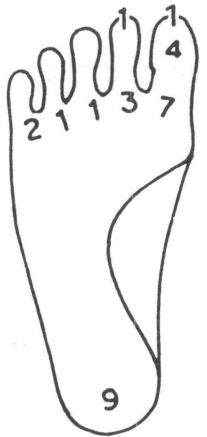

RIGHT 29

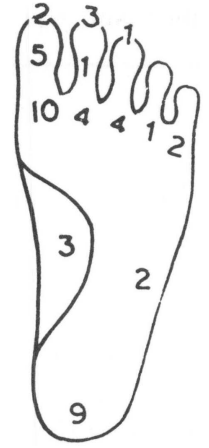

LEFT 47

Figure 1. Distribution of 89 ulcers.

The tape was applied directly on the ulcer, after cleaning the ulcer with plain water and air drying in the field. All patients were taught how to apply the tape and were made to practise in the presence of a doctor. Proper education about care of feet and hands was given to them. Patients were advised not to soak their feet daily since this would reduce the adhesive quality of the tape and necessitate daily changing of the dressing. A sufficient quantity of tape was supplied to the patients for reapplication once the previous tape started coming off. The effect of tape treatment was evaluated every week, until the ulcers healed. Patients were ambulatory for their work during the tape treatment. All the relevant information were recorded on predesigned proforma.

\section{Results}

\section{HEALING OF ULCERS WITH ADHESIVE ZINC TAPE TREATMENT}

The tape treatment stopped discharge from all four ulcers on the hand and $97 \%$ plantar ulcers in $3.5 \pm 1 \cdot 6$ and $5.1 \pm 4.3$ weeks, respectively (Table 1). Likewise, all the hand ulcers, and $82 \%$ plantar ulcers healed in $3 \cdot 8 \pm 2 \cdot 1$ and $9 \cdot 5 \pm 7 \cdot 6$ weeks of tape treatment, respectively (Table 2 ), while patients were ambulatory for their work.

All $14(18.4 \%)$ non-healed plantar ulcers, mostly on bony pressure points (Figure 2), became complicated while on tape treatment; of which 8 ulcers on heels and base of big toes developed sinus.

MATERIAL COST AND OPERATIONAL FEASIBILITY OF TAPE TREATMENT OF ULCERS

The average amount of adhesive zinc tape issued (and utilized), number of tape dressings applied, and estimated cost of tape to heal an ulcer, are given in Table 3. 
Table 1. Time taken to stop discharge from plantar ulcers

\begin{tabular}{lccccc}
\hline & & \multicolumn{4}{c}{ Plantar ulcers (\%) } \\
\cline { 2 - 6 } & $\begin{array}{c}\text { Time taken } \\
\text { (weeks) }\end{array}$ & $\begin{array}{c}\text { Small } \\
n=40\end{array}$ & $\begin{array}{c}\text { Medium } \\
n=09\end{array}$ & $\begin{array}{c}\text { Big } \\
n=16\end{array}$ & $\begin{array}{c}\text { Total } \\
n=65\end{array}$ \\
\hline & $1-4$ & $67 \cdot 50$ & $55 \cdot 55$ & $25 \cdot 00$ & $55 \cdot 38$ \\
& $9-8$ & $27 \cdot 50$ & $22 \cdot 22$ & $25 \cdot 00$ & $26 \cdot 16$ \\
& $13-25$ & $05 \cdot 00$ & - & $25 \cdot 00$ & $09 \cdot 24$ \\
Did not stop after 25 wk & - & $11 \cdot 11$ & $18 \cdot 75$ & $06 \cdot 15$ \\
& & - & $11 \cdot 11$ & $06 \cdot 25$ & $03 \cdot 08$ \\
\hline Total & $100 \cdot 00$ & $99 \cdot 99$ & $100 \cdot 00$ & $100 \cdot 00$ \\
\hline Average time (wk) to stop discharge & $3.6 \pm 2 \cdot 4$ & $5 \cdot 7 \pm 5 \cdot 2$ & $8 \cdot 7 \pm 5.5$ & $5 \cdot 1 \pm 4 \cdot 3$ \\
\hline
\end{tabular}

Table 2. Time taken to heal ulcer ( $\%)$

\begin{tabular}{|c|c|c|c|c|c|c|}
\hline \multirow[b]{2}{*}{$\begin{array}{l}\text { Time taken } \\
\text { (weeks) }\end{array}$} & \multicolumn{4}{|c|}{ Plantar ulcers } & \multirow[b]{2}{*}{$\begin{array}{l}\text { Hand ulcers } \\
\text { (all small) } \\
n=13\end{array}$} & \multirow[b]{2}{*}{$\begin{array}{l}\text { Grand total } \\
\quad n=89\end{array}$} \\
\hline & $\begin{array}{l}\text { Small } \\
n=62\end{array}$ & $\begin{array}{c}\text { Medium } \\
n=09\end{array}$ & $\begin{array}{c}\text { Big } \\
n=15\end{array}$ & $\begin{array}{c}\text { Total } \\
n=76\end{array}$ & & \\
\hline $1-4$ & $32 \cdot 69$ & $11 \cdot 11$ & $13 \cdot 33$ & $26 \cdot 32$ & $69 \cdot 20$ & $32 \cdot 58$ \\
\hline $5-8$ & $30 \cdot 77$ & $33 \cdot 33$ & $13 \cdot 33$ & $27 \cdot 63$ & $30 \cdot 80$ & $28 \cdot 09$ \\
\hline $9-12$ & $09 \cdot 62$ & - & $06 \cdot 67$ & $07 \cdot 89$ & - & $06 \cdot 74$ \\
\hline $13-25$ & $15 \cdot 38$ & $22 \cdot 22$ & $33 \cdot 33$ & $17 \cdot 73$ & - & $16 \cdot 86$ \\
\hline \multicolumn{7}{|l|}{ Not healed even after } \\
\hline 25 weeks treatment* & $11 \cdot 54$ & $33 \cdot 33$ & $33 \cdot 33$ & $18 \cdot 42$ & - & $15 \cdot 73$ \\
\hline Total & $100 \cdot 0$ & $100 \cdot 0$ & $100 \cdot 0$ & $100 \cdot 0$ & $100 \cdot 0$ & $100 \cdot 0$ \\
\hline Average weeks to heal ulcer & $8 \cdot 1 \pm 6 \cdot 6$ & $11 \cdot 0 \pm 9 \cdot 3$ & $14 \cdot 8 \pm 8 \cdot 9$ & $9 \cdot 5 \pm 7 \cdot 6$ & $3 \cdot 8 \pm 2 \cdot 1$ & $8 \cdot 5 \pm 7 \cdot 3$ \\
\hline
\end{tabular}

* All these 14 recurrent plantar ulcers for an average duration of $1 \cdot 4 \pm 1$ year were amongst 13 males ( $46 \pm 7$ years age) who walked about $4-5 \mathrm{~km}$ /day while working as agricultural labourers/ weavers (Figure 2).

Presuming that an ulcer will take the same time to heal with gauze and bandage treatment as with adhesive zinc tape; even then the gauze and bandage treatment at the rate of one dressing (minimum of Rs 1) per day may cost about 40 times more than tape treatment.

The adhesive zinc tape treatment of ulcers was found to be acceptable and convenient to patients and operationally feasible under field conditions. On average it took 4 minutes to completely dress an ulcer with tape, that is about 3 minutes for cleaning the ulcer with plain water and its air drying, and a further 1 


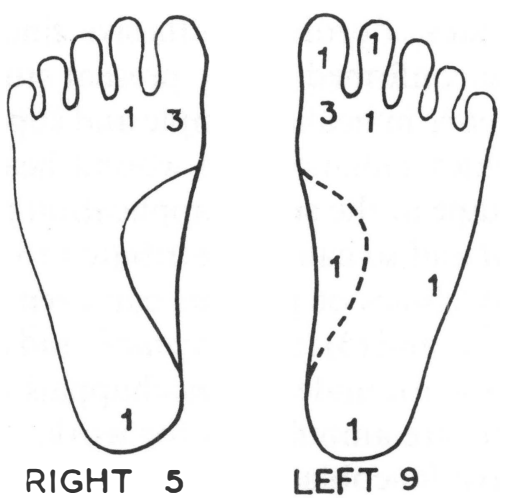

Figure 2. Distribution of ulcers not healed.

Table 3. Adhesive zinc tape issued, dressings applied and cost to heal ulcer

\begin{tabular}{|c|c|c|c|c|c|}
\hline \multirow[b]{2}{*}{ Average } & & \multicolumn{4}{|c|}{ Ulcers } \\
\hline & & Small & Medium & Big & Total \\
\hline Tape issued $(\mathrm{cm})^{*}$ & & $196 \cdot 1 \pm 171 \cdot 6$ & $246 \cdot 4 \pm 277 \cdot 8$ & $509 \cdot 4 \pm 201 \cdot 3$ & $200 \cdot 7 \pm 284 \cdot 3$ \\
\hline Tape dressings applied (number) & $\begin{array}{c}\text { Total } \\
\text { Per week }\end{array}$ & $\begin{array}{c}16 \cdot 0 \pm 18 \cdot 5 \\
2 \cdot 1 \pm 2 \cdot 6\end{array}$ & $\begin{array}{c}30 \cdot 0 \pm 37 \cdot 7 \\
2 \cdot 9 \pm 3 \cdot 6\end{array}$ & $\begin{array}{c}45 \cdot 7 \pm 36 \cdot 3 \\
3 \cdot 7 \pm 3 \cdot 3\end{array}$ & $\begin{array}{c}21 \cdot 5 \pm 25 \cdot 7 \\
2 \cdot 4 \pm 2 \cdot 9\end{array}$ \\
\hline Tape cost (Rs) to heal ulcer** & & $1 \cdot 6 \pm 1 \cdot 4$ & $1 \cdot 9 \pm 2 \cdot 2$ & $4 \cdot 1 \pm 1 \cdot 6$ & $1 \cdot 6 \pm 2 \cdot 3$ \\
\hline
\end{tabular}

* More than $95 \%$ of issued tape was utilized by patients for dressing their ulcers.

** Cost worked out on market price (1984) of ordinary adhesive leucoplast (tape) at rate of Rs 4/- per roll of $2.5 \mathrm{~cm} \times 5 \mathrm{~m}$.

minute to apply the tape to the ulcer. No local allergic reaction due to tape was noticed.

\section{Discussion}

The dressing of ulcers with medicament, gauze and bandage is not only much costlier but also creates obvious problems to medical teams as well as patients. ${ }^{8}$ Application of below-knee plaster of Paris also takes about 6-8 weeks to heal an uncomplicated superficial and discharge-free plantar ulcer. Besides the cost and expertise needed to apply the plaster, it makes the patients associate the healing of ulcers with plaster rather than with foot care, thus it is more likely to reulcerate. Moreover, at times POP predisposes the bones for disuse osteoporosis and fractures of bones. ${ }^{5}$ 
However, the advantages of ordinary adhesive zinc tape treatment of ulcers, as reported earlier, ${ }^{6,8}$ are confirmed by the present study and also that the tape treatment is (1) quite effective in healing simple and superficial ulcers, on account of its (a) zinc content which enhances the wound healing process, and (b) the longer stay (sticking) of tape at the site of application prevents ulcer contamination, (2) more economical and so can be distributed to all ulcer patients through outpatient mobile leprosy clinics or patients can even purchase the tape from a market whenever necessary, and (3) it is acceptable and convenient to patients as it can be easily applied and worn under shoes/chappals without any problem and stigma, and while patients are ambulatory for work.

The available adhesive leucoblast may be used in treating uncomplicated superficial ulcers in field and hospital situations, and is better if fixed on thin polythene sheets for easy distribution and application by patients.

In the present study, the non-healing of about $18 \%$ of plantar ulcers in spite of 25 weeks of tape treatment (Table 2) could be for a variety of reasons: (1) site of the ulcer was on the constant pressure point (Figure 2), (2) an underlying primary cause of ulcer(s) which needed to be rectified, and (3) carelessness on the part of the patient in the care of his limbs and ulcer; and not necessarily due to failure of tape treatment. Likewise, the regular use of MCR-footwear by the patients with anaesthetic feet could certainly help in reducing the duration of tape treatment to heal, and to prevent the recurrence of plantar ulcer(s).

In conclusion it is necessary to emphasize that there is no better treatment to cure and prevent ulceration and deformities, than continuous health education and motivation of patients for regular treatment and proper care of limbs.

\section{Acknowledgments}

The adhesive zinc tape used in this trial was received under SIDA assistance to NLCP through the Directorate General of Health Services, New Delhi. The project was carried out under the 'ICMR Unit for Special Studies in Leprosy' attached to our Institute. The guidance received during the planning and carrying out of this project from Dr H Srinivasan, former Deputy Director (Orthopaedics) of our Institute, is gratefully acknowledged. The statistical assistance of $\mathrm{Mr} \mathrm{V}$ Chandrasekaran, and the secretarial assistance of $\mathrm{Mr} \mathrm{T}$ Sridharan and $\mathrm{Mr} \mathrm{R}$ Perumal are acknowledged with thanks.

\section{References}

${ }^{1}$ Gilje O. Ulcus Cruris in venous circulatory disturbances. Acta Dermatovener Suppl, 1949; 22:

${ }^{2}$ Hallmans G. Wound healing with adhesive zinc tape. An animal experimental study. Scand $J$ Plast Reconstr Surg, 1971; 10: 1977. 
${ }^{3}$ Hallmans G. Absorption of topically applied zinc and changes in zinc metabolism during wound healing. Acta Dermato-Venerologich, 1978; 58: Suppl. 80.

${ }^{4}$ Hallmans G, Hanstrem L, Lundgren E. The effect of zinc tape upon wound healing in rats. A biochemical histochemical and histological study. Scand J Plast Reconstr Surg, 1979; 13: 257.

${ }^{5}$ Pring DJ, Casiebanca N. Simple plantar ulcers treated by below knee plaster and moulded double-rocker. Lepr Rev, 1982; 53: 261-4.

${ }^{6}$ Soderberg T. et al. Treatment of leprosy wounds with adhesive zinc tape. Lepr Rev 1982; 53:2716.

7 Stenstrom S, Bergman G, Bergman S. Wound healing with ordinary adhesive tape. Scand J Plast Reconstr Surg, 1978; 6: 40.

${ }^{8}$ Stenstrom S, et al. Leprosy wound healing with ordinary adhesive tape. A preliminary report. Scand J Plast Reconstr Surg, 1976; 10: 241.

9 Widere S, Sarbe Handling, Osto. 1925 (Quoted by Sorderberg et al, 1982). 